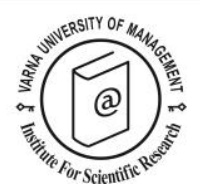

\title{
Frequency domain causality analysis of tourism and economic activity in Turkey
}

\author{
Hasan Gül ${ }^{1 *}$ and Mustafa Özer ${ }^{2}$
}

\section{Received: 04/08/2017 Accepted: 26/11/2017}

\footnotetext{
${ }^{1}$ Adana Science and Technology University, Faculty of Business, Department of Tourism Management, Adana/Turkey. E-mail: hgul@adanabtu.edu.tr

${ }^{2}$ Anadolu University, Faculty of Economics and Administrative Sciences, Department of Economics, Eskişehir/Turkey. E-mail: muozer@anadolu.edu.tr

* Corresponding author
}

\section{Abstract}

This paper studies the dynamic relationships between real Gross Domestic Product (GDP), real exchange rate (RER) and real tourism income (TOTREC) in Turkey over the period from 2003: Q1 to 2014: Q4 by using frequency domain causality approach developed by Breitung and Candelon (2006). Our findings reveal that real GDP Granger causes real tourism income both in the short-and long-run, while real tourism income only Granger causes real GDP in the short run. Moreover, there is no Granger causality neither between real tourism income and real exchange rate nor between real GDP and real exchange rate. These findings support Tourism-led Growth Hypothesis (TLGH) only in the short-run. Therefore, there is an urgent need to develop and implement appropriate tourism policies so that the sector's contribution to economic growth can be extended to long-run.

(C) 2018 Varna University of Management. All rights reserved

Keywords: Frequency domain Granger causality, Time domain (conventional) causality, Real Tourism Incomes, Real Exchange Rate, Real GDP, Turkey.

Citation: Gül, H., M. Özer (2018) Frequency domain causality analysis of tourism and economic activity in Turkey. European Journal of Tourism Research 19 pp. 86-97

\section{Introduction}

The importance of tourism sector has increased for many decades and become a remedy especially for developing countries' economic progress in the world. Demand for international tourism has remained robust in almost each year despite the economic and political crises and natural disasters. The amount of international tourists reaches a total of 1.235 billion in 2016 according to World Tourism Barometer published by the World Tourism
Organization-UNWTO (UNWTO, 2017). When compared to the year of 2015 , there is a $3.9 \%$ increase in the world tourist movements.

From an economic point of view, there are three main principles that underlie the concept of tourism. First, as an industry, tourism generates income, revenue, and employment. Second, tourism is a form of an international trade, which provides a source of foreign exchange as an important component for many countries' 
national balance of trade. Third, tourism acts according to the principles of demand and supply (Nuryanti, 1998:44). Correspondingly, tourism generates $9 \%$ of world GDP, $6 \%$ of the world exports (including passenger transport), which value of \$US 1.3 trillion and creates 1 in 11 jobs in the labour market (UNWTO, 2016).

Over the past four decades, the tourism sector of Turkey has developed rapidly. As an economic sector, tourism has contributed to economy and Turkey consistently ranks among the most tourist attracting countries in the world for many years. Although, it was $\$ 36,2$ billion in 2015, Turkey's tourism revenue diminished to $\$ 25.3$ billion in 2016, mainly caused by diplomatic crisis between Russia and Turkey erupted in 2015, regional uncertainties around the Turkey mostly arising from Syrian conflict and failed 15 July coup attempt in 2016. This significant fall in tourism revenues created serious adverse effects on the Turkish economy especially putting a lot of pressures on Turkish Lira to depreciate against major currencies. Turkish tourism sector now seeking for new policies to attract new tourist arrivials from European countries and around different regions of the world to increase the contribution of the sector to economy.

This paper contributes to the literature in twofold. First of all, to the best of our knowledge, this is the first attempt anlyising the relations between real GDP, real tourism receipts and Real exchange rate by using frequency domain causality tests (Breitung \& Candelon, 2006). Secondly, unlike to the previous studies like Belloumi (2010) and Katircioglu (2009) that rely on a single statistic using conventional time domain analysis, we prefer to use the frequency domain approach which allows investigating causality dynamics at different frequencies. In the time domain analysis carried out within the framework of a Vector Autoregression (VAR) model, it is assumed that a single statistic can be used to explain the relations among the variables at all frequencies. However, this single statistic never differentiates between the causalities at higher and lower frequencies.

This paper is organized as follows. Section 2 briefly surveys the literature on Granger causality tourism studies (using both time and frequency domains) in the world. Afterwards, theoretical framework of Granger causality in the frequency domain testing is summarized in the third section. This study covers quarterly Turkish data from 2003 to 2014 and Section 4 describes data which we employed in the estimation. Empirical findings of the frequency domain approach of causality are displayed in the fifth section. The last part discusses results and concludes the paper with some remarks.

\section{Literature review}

Tourism studies analyze different types of models and assumptions in the literature based on the subjects, data and variables with some econometric and testing methods. A large body of tourism studies has been published in the past few decades. Literature review of this study gives attention to papers which related to the Granger causality in both time and frequency domains in the world. We notice that the majority of the Granger causality studies generally reveal dynamic processes and investigate the linkages among GDP, exchange rate, tourist arrivals, tourism receipts and so on.

Granger causality tests with time series data are the most widely employed technique in this field. It has been reported that existing literature has mainly two hypotheses which are tested by employing the Granger causality. Firstly, tourism growth contributes economic expansion. As Pavlic et al. (2015) indicates that if tourism growth has some positive effects on GDP, employment, foreign exchange earnings and government revenues, we define it Tourism-Led Growth Hypothesis (TLGH).

The great majority of studies provide evidence supporting the TLGH. Balaguer and CantavellaJorda (2002) was the first study to investigate the TLGH by employing the Granger causality test for Spain. Afterwards, most studies confirm the validity of TLGH although they used different countries, data span and methods. These studies chronologically are: Dritsakis (2004) for Greece; Durbarry (2004) for Mauritius; Brida, Sanchez Carrera and Risso (2008) for Mexico; Brida, Pereyra and Devesa (2008) for Argentina, Brazil, Uruguay and Mexico; Akinboade and Braimoh (2010) for South Africa; Belloumi (2010) for Tunisia; Katircoglu (2010) for North Cyprus; Cortes-Jimenez and Pulina (2010) for 
Frequency domain causality analysis of tourism and economic activity in Turkey.

Italy and Spain; Schubert et al. (2011) for Antigua and Bermuda; Li et al. (2013) for Malaysia; Ridderstaat et al. (2014) for Aruba; Kumar (2014) for Kenya; Tang and Tan (2015) for Malaysia; Pavlic et al. (2015) for Croatia; Phiri (2016) for South Africa; Tang and Abosedra (2016) for Lebonan; Kumar and Stauvermann (2016) for Sri Lanka; Tang and Özturk (2017) for Egypt; Ohlan (2017) for India and Shahzad et al.(2017) for ten countries. In these countries (mostly developing ones) tourism activity is expected to be an important spur of economic growth. Several studies such as Yıldırım and Öcal (2004); Gunduz and Hatemi (2005); Demiröz and Ongan (2005); Gokovali (2010); Arslanturk et al. (2011); Arslanturk (2012), Ertugrul and Mangir (2015); Aslan (2016) show evidence supporting TLGH for Turkey as well.

On the other hand, some papers rejected the TLGH because they found that conversely economic expansion affects tourism growth in some countries (Oh, 2005:42). Among these studies are Oh (2005) for South Korea; Katircioglu (2009) for Turkey; Jackman and Lorde (2010) for Barbados; Kasimati (2011) for Greece; Ghosh (2011) for India; Kumar and Kumar (2012) for Fiji.

Frequency domain analysis is a quite new approach and to our knowledge, there is no study, examining the dynamic relationships which used the frequency domain causality approach in tourism. Thus, this article will offer a good example of short, medium and long-run comovement in tourism.

\section{Methodology}

Granger (1969) introduced causality approach to define temporal causal relations among multivariate time series variables (Liu and Molenaar, 2016:53). This approach determines the model and some coefficients of this model which relevant to past and current values of $X$ and investigates their significance (Ozer and Kamisli, 2015). Thus, this test is easy to conduct, and the simplicity of this approach makes it desirable to apply in the regression model. As is indicated in Krätschell and Schmidth (2012), Granger causality test is not appropriate for differentiating between long run and short run effects in most cases due to its mostly based on one period ahead predictions. In other words, the extent of causality can be different between frequency bands and conventional causality tests are not able to recognize as a result of these reasons (Clive and Lin, 1995).

Ding et al. (2006) suggested that to reach a dynamic (short-, medium- and long-run) Granger causality, the use of the frequency domain causality is more appropriate approach (Ozer and Kamisli, 2015:178). Because, it allows to estimate the causal relationship for different frequencies (temporary and permanent causality). For these reasons, this paper aims to propose a model for the frequency domain Granger causality.

Frequency domain causality refers to a method of frequency-wise testing for causation for systems involving nonstationary variables and possible cointegration. As is explained in Tiwari et al. (2015), the term frequency domain is used to describe the domain for analysis of mathematical functions or signals with respect to frequencies, rather than time. In the frequency domain, one can express a stationary process as a weighted sum of sinusoidal components with a certain frequency $(\omega)$. In the frequency domain, we can use the similar of the Granger causality, as in the time domain. In non-technical terms, although how a signal changes over time is visualized by a time-domain graph, a frequency-domain graph illustrates how much of the signal lies within each given frequency band over a certain range of frequencies. According to Tiwari et al. (2015), while "time" refers to ability of indicating when a certain variation happens, "frequency" should be considered as a component which measures the degree of a certain variation. What Breitung and Candelon (2006) approach is to interpret the frequency domain Granger causality as a decomposition of the total spectral interdependence between the two series into a sum of "instantaneous", "feedforward" and "feedback" causality terms. These authors show that the frequency domain causality tests be calculated by imposing linear restrictions on the autoregressive parameters in a VAR model, permitting to test for informational linkages at any frequency. 
The measurement of causality introduced by Geweke (1982) and Hosoya (1991) can be shown below:

$$
\begin{aligned}
& M_{Y \rightarrow X}(\omega)=\log \left[\frac{2 \pi f_{X}(\omega)}{\left|\psi_{12}\left(e^{-i \omega}\right)\right|^{2}}\right] \\
& =\log \left[1+\frac{\left|\psi_{12}\left(e^{-i \omega}\right)\right|^{2}}{\left|\psi_{11}\left(e^{-i \omega}\right)\right|^{2}}\right]
\end{aligned}
$$

If the numerator of equation (2) $\psi_{12}\left(e^{-i \omega}\right)=0$, mathematically, $M_{Y \rightarrow X}(\omega)$ become zero and infer that variable of $Y$ does not Granger cause to variable $X$ at frequency $\omega$. For that reason, if the numerator of equation (2) $\psi_{12}\left(e^{-i \omega}\right)=0$, we consider that no Granger causality at $\omega$ frequency.

Therefore, the null hypothesis for testing the $Y$ does not Granger cause $X$ within a bivariate framework depended on Geweke measure is suggested in equation (3) as shown:

$$
H_{0}: M_{Y \rightarrow X}(\omega)=0
$$

Tracking of the Breitung and Candelon (2006) article, we test $\mathrm{H}_{0}$, that is $\mathrm{Y}$ does not Granger cause $X$ at frequency $\omega$, so assume that this hypoythesis $H_{0}: M_{Y \rightarrow X}(\omega)=0$ is equal to the linear restriction

$$
H_{0}: R(\omega) \beta=0
$$

with $\beta=\left[\beta_{1}, \ldots, p\right]^{\prime}$ and

$R(\omega)=\left[\begin{array}{llll}\cos (\omega) & \cos (2 \omega) & \ldots & \cos (p \omega) \\ \sin (\omega) & \sin (2 \omega) & \ldots & \sin (p \omega)\end{array}\right]$

In this study, for testing the null hypothesis of Granger causality at $\omega$ frequency, we test the standard F- statistics. This statistics is distributed as $F(2, T-2 p)$ for $\omega \epsilon(0, \pi)$, where 2 stands for the number of restrictions and $T$ means the number of observations which employed to measure the VAR model of order $p$ (Ozer and Kamisli, 2015:180). Notice that Fstatistics is a function of $\omega$, which allows the performance of the causality test for cycles at different frequencies. At $\omega=0, \pi$ the second row in Equation (5) is identically zero so that only a single restriction applies. In this case the test statistic becomes $\mathrm{F}[1, \mathrm{~T}-2 \mathrm{p}]$.

\section{Data and preliminary analysis}

This article aims to contribute the existing literature by measuring Granger causality in frequency domain of tourism on economic growth in Turkey. This section summarizes the complete description of the data used in the study. The variables used in this study represent indicators of Turkish economic growth and earnings from international tourism. Data used in the econometric analysis were obtained from large external sources. The first source of data corresponds to real tourism receipts were derived from the departing visitors' survey conducted by Turkish Statistical Institute (TSI). The most appropriate measure of income $(\mathrm{Y})$ is the GDP in the country. The real GDP data was obtained from TSI as well and they appeared in fixed 1998 prices in data set. Real exchange rate for Turkey collected from Central Bank of Republic of Turkey (CBRT). All data is at a quarterly frequency and starts from 2003 to 2014. Real tourism receipts and real GDP values are expressed in US\$.

Figure 1 plots both the logarithmic values of all variables and seasonally adjusted values of GDP and TOTREC.

As is seen in Figure 1, since both GDP and TOTREC are exhibiting strong seasonality, we remove the seasonality in these series by using TRAMO/SEATS method. And also, all series have structural breaks in different dates, which should be taken into account when we carry out unit root tests.

Table 1 summarizes the descriptive statistics for the varaibles used in the study. The average values of all variables are positive. The value of the skewness is negative for RER, indicating that depreciation of Turkish lira is less common than appreciation of Turkish Lira during the examination period. Furthermore, the kurtosis statistic value for GDP is greater than three indicating that it is leptokurtic. Finally, JarqueBera (JB) test statistics indicate that all series have a normal distribution, since probability values of each JB statistics greater than $5 \%$ level of significance. 
LGDP

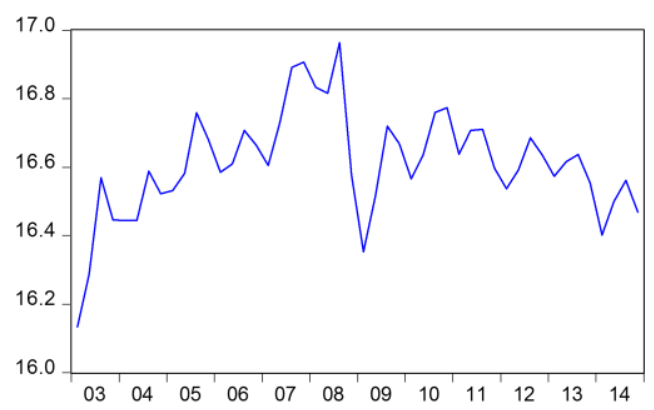

LTOTREC

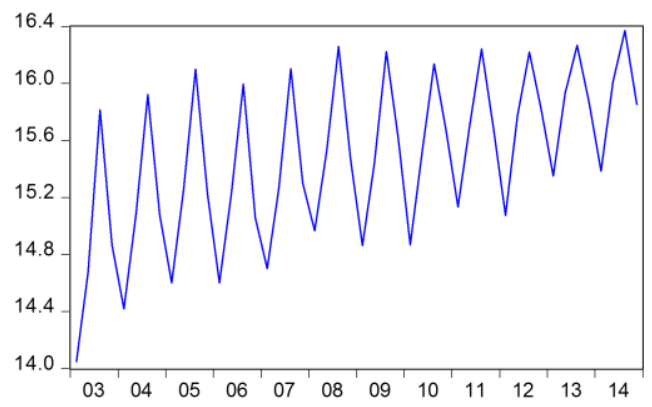

LRER

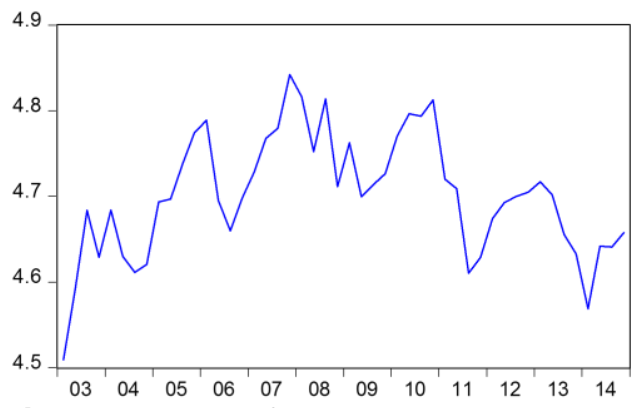

LGDP_SA

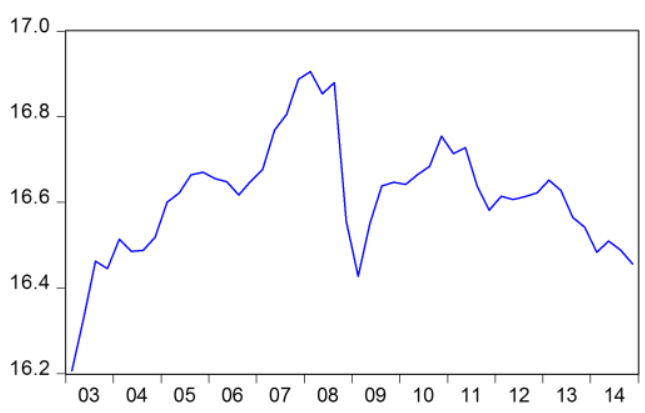

LTOTREC_SA

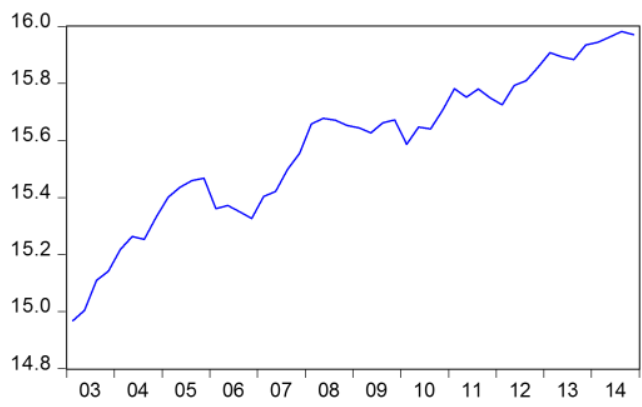

Figure 1. Plots of variables

Table 1. Descriptive statistic

\begin{tabular}{lccc} 
& GDP & TOTREC & RER \\
\cline { 2 - 4 } Mean & 16544049 & 6040379 & 110.3275 \\
Maximum & 23274883 & 12854373 & 126.7500 \\
Minimum & 10157957 & 1261787 & 90.85000 \\
Std. Dev. & 2526572 & 3118651 & 7.811587 \\
Skewness & 0.301052 & 0.486917 & -0.012745 \\
Kurtosis & 3.680875 & 2.118817 & 2.663947 \\
Jarque-Bera(JB) (Prob) & $1.652237(0.43)$ & $3.449670(0.17)$ & $0.227163(0.89)$ \\
\hline
\end{tabular}

Table 2 reports the unconditional correlation of the variables. We can observe that the highest correlation is between the GDP and RER (72\%) while surprisingly the lowest is between RER and TOTREC (about 0.005\%). 
Table 2. Correlations of variables

\begin{tabular}{cccc} 
& GDP & TOTREC & RER \\
\hline GDP & 1 & & \\
TOTREC & 0.46 & 1 & \\
RER & 0.72 & 0.005 & 1 \\
\hline
\end{tabular}

\section{Empirical Results}

Since before carrying out Granger causality tests, we need to know degree of the integration of the variables and whether or not they are cointegrated. To determine the degree of the integration of each variable, we first carry out traditional unit root tests of Augmented DickeyFuller (ADF) and Kwiatkowski-PhillipsSchmidt-Shin (KPSS) tests. Also, we use break point unit root test provided by Eviews 9.51 . After finding that all series are integrated of order one with structural break, we test the presence of cointegration between the variables by using Johansen cointegration tests. To carry out these tests, we first determine lag length by using Akaike information criterion (AIC). Finally, we apply several diagnostic tests including heteroscedasticity and serial correlation in the errors of VAR in Eq (1). All the test results confirmed that the error term is white noise. After determining the time series properties of the variables, we carried out both conventional Granger causality test and the frequency domain Granger causality test of Breitung and Candelon (2006) and Table 3 presents the results and conclusions of these tests. Before implementing the frequency domain Granger causality test, we try to determine the direction of causal relationships among real GDP, real exchange rate and real tourism income employing VAR Granger causality test applied as Wald test to investigate the short-run dynamic relations among related variables.

Table 3 summarizes the results of Granger causality tests as time domain (conventional) and frequency domain ones.

Based on the results in Table 3 , we can conclude that there exists a bi-directional causality between real tourism income and real GDP in Turkey. However, the results do not indicate any causal relations between real tourism income and real exchange rate, and between real exchange rate and real GDP.

Unfortunately, time domain (conventional) Granger causality tests between real tourism income and real GDP are unable to indicate clearly whether the co-movement is a result of short-term fluctuations or long-term. Namely, as indicated in Ciner (2011), the conventional Granger causality test implicitly ignores the fact that the possibility of causal dynamics can show variation across different frequencies and give a single one-short statistical result regarding its predictability. Thus, to understand the possible

Table 3. Time domain (Convetional) and frequency domain Granger causality test results Frequency-domain

\section{Conventional}

\section{Long-term Medium-term}

Short-term

$\begin{array}{lll}\text { LTOTRECSA } \neq>\text { LRER } & 0.2865 & \mathrm{x} \\ \text { LRER } \neq>\text { LTOTRECSA } & 0.3560 & \mathrm{x} \\ \text { LTOTRECSA } \neq>\text { LGDPSA } & \mathbf{0 . 0 5 3 0 ^ { * * }} & \mathrm{x} \\ \text { LGDPSA } \neq>\text { LTOTRECSA } & \mathbf{0 . 0 1 4 8 ^ { * }} & \mathrm{x} \\ \text { LRER } \neq>\text { LTOTRECSA } & 0.4808 & \mathrm{x} \\ \text { LTOTRECSA } \neq>\text { LRER } & 0.5364 & \mathrm{x}\end{array}$

$\omega=0.05$
$x$
$x$
$x$
$\sqrt{ }$
$x$
$x$

$\omega=1.0$
$x$
$x$
$x$
$x$
$x$
$x$

$\omega=1.5$
$x$
$x$
$x$
$x$
$x$
$x$

$\begin{array}{cc}\omega=2.0 & \omega=2.5 \\ x & x \\ x & x \\ x & \sqrt{ } \\ \sqrt{ } & \sqrt{ } \\ x & x \\ x & x\end{array}$

Notes:

i. ${ }^{\star}$ and ${ }^{\star *}$ denote significance at $5 \%$ and $10 \%$ respectively.

ii. $\sqrt{ }$ and $X$ indicate the presence of Granger causality and non-causality respectively.

iii. LTOTRECSA $\neq>$ LRER denotes the null hypothesis $=\mathrm{H}_{0}$ : LTOTRECSA Doesn't Granger Cause LRER.

LRER $\neq>$ LTOTRECSA denotes the null hypothesis $=\mathrm{H}_{0}$ : LRER Doesn't Granger Cause LTOTRECSA.

iv. LTOTRECSA $\neq>$ LGDPSA denotes the null hypothesis: $\mathrm{H}_{0}$ : LTOTRECSA Doesn't Granger Cause LGDPSA.

LGDPSA $\neq>$ LTOTRECSA denotes the null hypothesis: $\mathrm{H}_{0}$ : LGDPSA Doesn't Granger Cause LTOTRECSA.

v. LRER $\neq>$ LGDPSA denotes the null hypothesis: $\mathrm{H}_{0}$ : LRER Doesn't Granger Cause LGDPSA.

LGDPSA $\neq>$ LRER denotes the null hypothesis: $\mathrm{H}_{0}$ : LGDPSA Doesn't Granger Cause LRER. 
causes of the co-movement, we have to focus on the results of Granger causality test in frequency domain.

Table 3 also reports frequency domain test results, for all frequencies, $\omega$, (which are expressed as a fraction of $\pi)$ in the interval $(0$, $\pi)^{2}$. Frequency domain test results support the results of time domain Granger causality test as seen in Table 1. We observe that frequency domain approach gives much better information on the strengths and directions of causalities between real tourism income and real GDP in different frequencies, which have never been given before.

According to test results of frequency domain, we firstly observe that real GDP has significant causal effects on real tourism income at both short-term (frequency $\omega>1.8$ (4 quarters) and long-term (frequency $\omega<0.8$ (8 quarters). This suggests that real GDP has connections with real tourism income at the both low and high frequency. Secondly, real tourism income
Granger causes real GDP at high level of frequencies (that is frequency $\omega>2.2$ (3 quarters) implying the existence of a short-term causal relationships from real tourism income to real GDP. Therefore, as a result of decomposing the causality into different frequencies, our study provides a much deeper enlightenment of causal relationships between real tourism income and GDP.

We can get the clearer picture of Granger causality test in frequency domain by examining figures of test results. From Figures 2 to 4, the causality among tourism income, real exchange rate and real GDP in frequency domain are presented, with their $5 \%$ critical value (blue lines parallel to the frequency axis) for all frequencies $(\omega \in(0, \pi))$. Figure 2 demonstrates the causality measures between tourism income and real exchange rate.

The visual examination of Figure 2 reveals the fact that, as conventional Granger causality test results indicated, we fail to reject the null

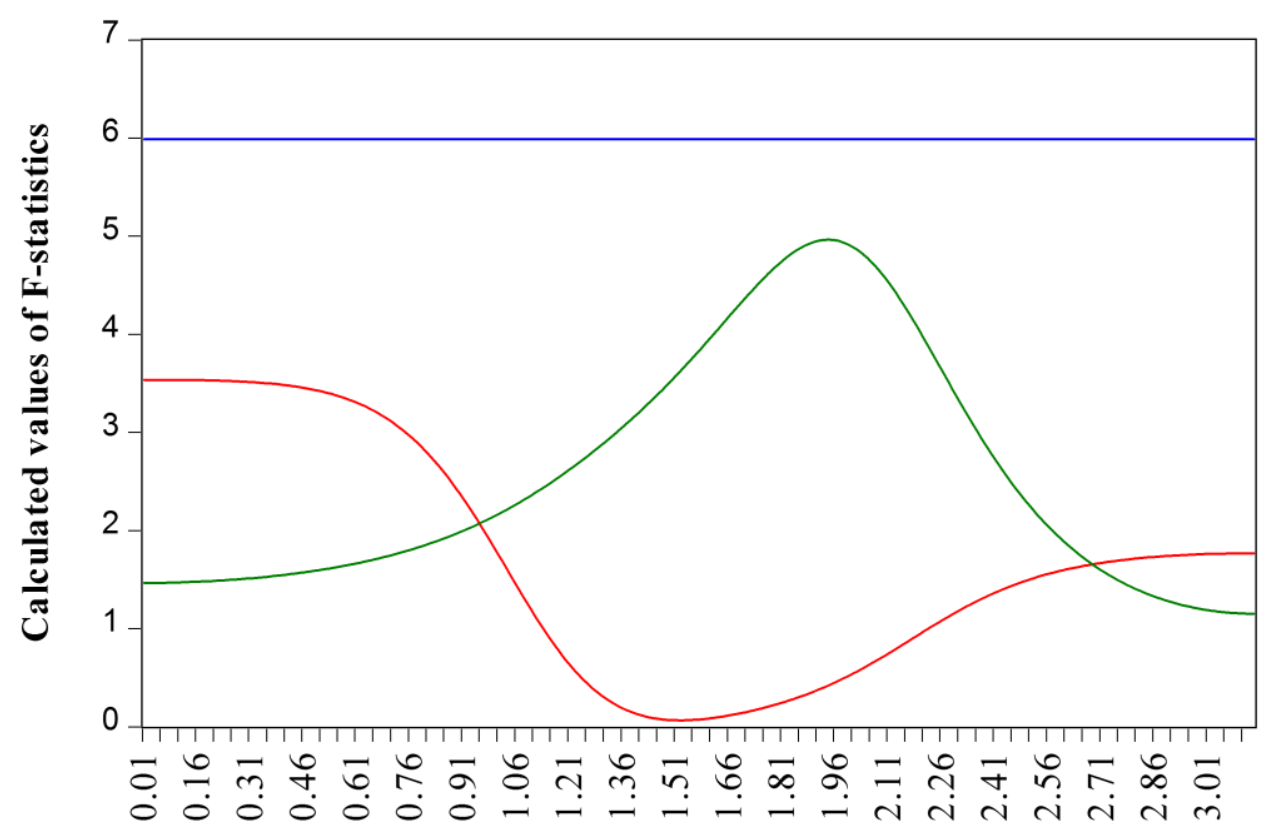

Frequency

BC Critical Value
BC Test Statistics (LRER does not cause LTOTRECSA)
BC Test Statistics (LTOTRECSA does not cause LRER)

Figure 2. Granger non-causality tests between tourism income and real exchange rate in frequency domain 
hypothesis of non-causality for any frequency in both directions. Thus, we can conclude that there is no evidence of Granger causality between tourism income and real exchange rate neither in time domain nor in frequency domain.

In Figure 3, we report the results of the Granger causality test in frequency domain between tourism income and real GDP.

Figure 3 provides evidences of business cycle causality for both directions as we discussed above. In other words, in the short-term, tourism income Granger causes real GDP; but, real GDP does Granger cause tourism income in both short-and long-term in frequency domain.

In Figure 4, we report the results of the Granger causality test in frequency domain between real GDP and real exchange rate.

Since the computed values of both frequency domain test statistics are less than table critical value of 5.99, we do not reject the null hypothesis of non-Granger causality between real exchange rate and real GDP in both directions. Unlike to the previous studies like Belloumi (2010) and Katircioglu (2009) that rely on a single statistic using conventional time domain analysis, we prefer to use the frequency domain approach and we only found an evidence of short-and long-run causality between GDP and TOTREC.

\section{Conclusion}

In this study, we apply the both time domain (conventional) and frequency domain Granger causality testing approach to investigate relationships among real GDP, real exchange rate and real tourism income for Turkey by using the data from 2003 to 2014. The results of conventional causality tests indicate the existence of a bi-directional causality between real tourism income and real GDP, and likewise, the results of Granger causality tests in frequency domain support the results of conventional (time domain) Granger causality test.

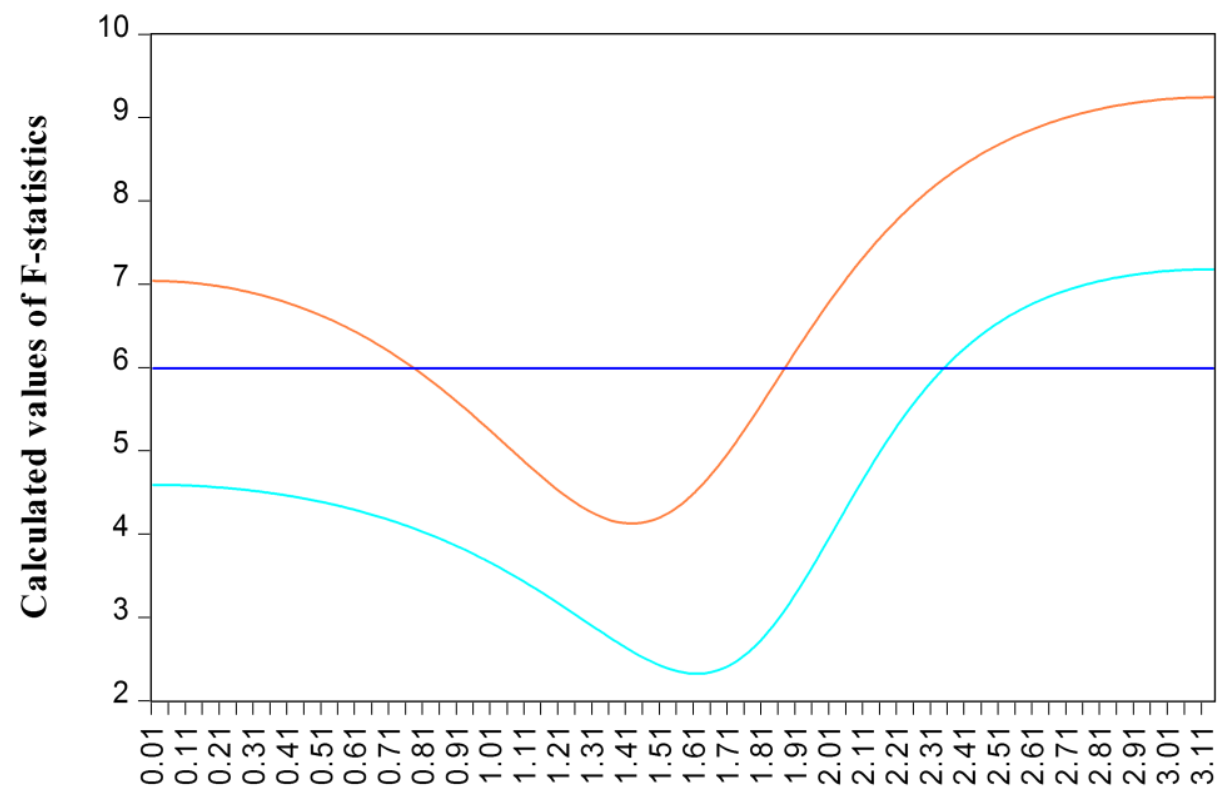

Frequency

BC Test Statistics (LGDPSA does not cause LTOTRECSA)
BC Test Statistics (LTOTRECSA does not cause LGDPSA)
BC Critical Value

Figure 3. Granger non-causality tests between tourism income and real exchange rate in frequency domain 
Frequency domain causality analysis of tourism and economic activity in Turkey.

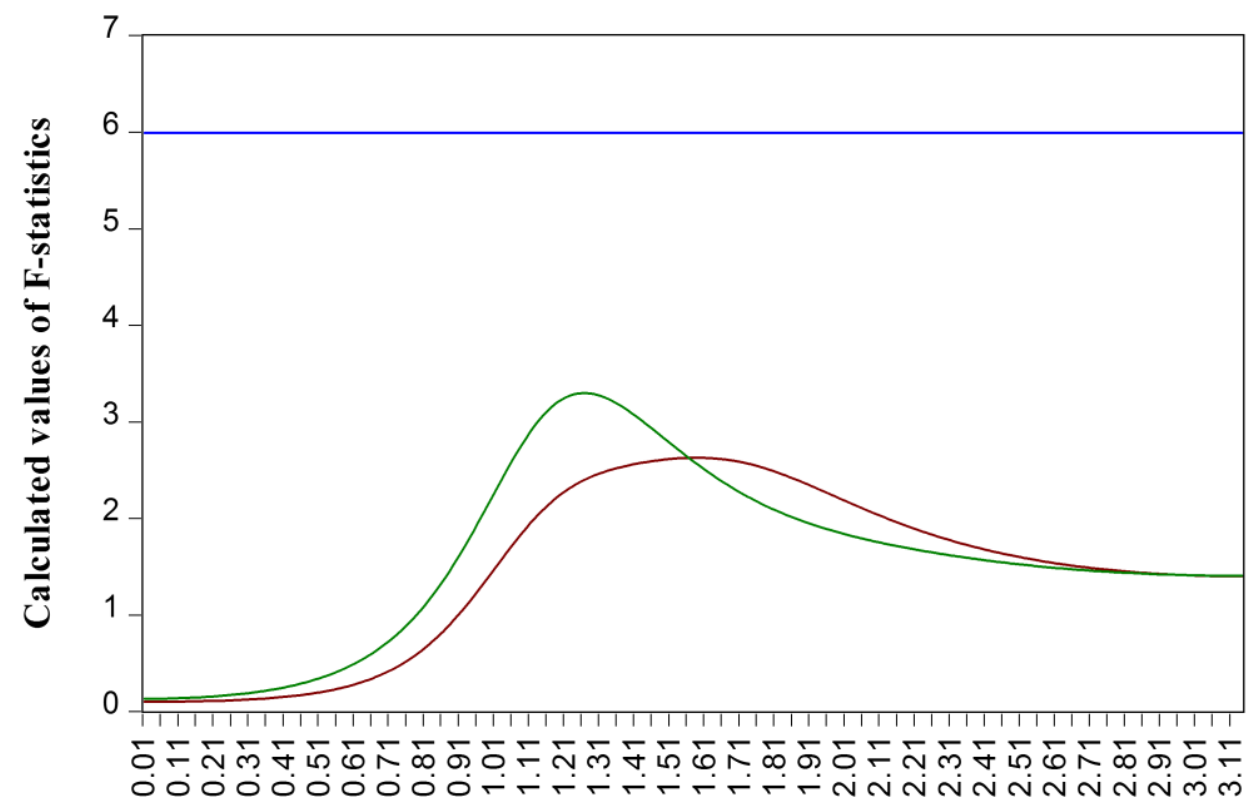

Frequency

BC Critical Value

BC Test Statistics (LGDPSA does not cause LRER)

BC Test Statistics (LRER does not cause LGDPSA)

Figure 4. Granger non-causality tests between real GDP and real exchange rate in frequency domain

As the frequency domain causality test results indicate that there exists bi-directional causality between tourism income and real GDP for Turkey in the short-term. This means that tourism influence economic growth in the shortterm. We conclude that, this paper supports the tourism-led growth hypothesis (TLGH) for Turkey. Moreover, results suggest that the importance of tourism sector to Turkish economy it is not deniable. These results are quite consistent with findings from the literature; however, we diagnose some divergences as well. However, it can be also observed that real GDP Granger cause real tourism income both in short- and long-term and no Granger causality neither between real tourism income and real exchange rate nor between real GDP and real exchange rate. Since the share of Turkish tourism industry in GDP increases for three decades, the long-run contribution of economic growth to tourism is expected. In addition to this, because of its multidimensional structure, tourism is less affected from economic crisis as a non-imported sector.
Two essential policy implications can be drawn from this study. Firstly, tourism serves as a short term source for economic growth in Turkey. Thus, policy-makers should encourage the development of the tourism industry by investing in infrastructure and tourist resorts to increase economic growth in Turkey. And to fully benefit from the TLGH model, the Ministry of Tourism in Turkey should come out with more competitive tourism packages to increase external competitiveness for attracting tourists across the globe. These are essential for Turkey to benefit by the promotion of tourism growth.

Secondly, the results from the findings indicate that there is no effect of real exchange rate on tourism income. The depreciation and/or appreciation of the exchange rate may probably have positive or negative impacts on the tourism industry. However, the overall performance of the tourism sector seems to indicate that such effects have been offset by other factors in the economy. 
Further studies can be done on identifying the factors that offset the effects of real exchange rate on tourism income in Turkey. Thus, policymakers should understand that targeting a more competitive exchange would not help to stimulate tourism industry in Turkey and they should aim at encouraging the development of tourism to achieve the all positive effects of tourism on the economy.

\section{Endnotes:}

1 The results of unit root tests and cointegration tests were not reported here to save the space but can be available on request.

2 The frequency, $\omega$, can be translated into a cycle or periodicity of $T$ quarters by $T=2 \pi / \omega$, where $T$ is the length of the period (in this study represents quarter). The higher the frequency, the lower the time period.

\section{References}

Akinboade, O. A., \& Braimoh, L. A. (2010). International tourism and economic development in South Africa: A Granger causality test. International Journal of Tourism Research, 12(2), 149-163.

Arslanturk, Y. (2012). Dynamic relation between economic growth, foreign exchange and tourism incomes: An econometric perspective on Turkey. Journal of Business Economics and Finance, 1(1), 30-37.

Arslanturk, Y., Balcilar, M., \& Ozdemir, Z. A. (2011). Time-varying linkages between tourism receipts and economic growth in a small open economy. Economic Modelling. 28(1), 664-671.

Aslan, A. (2016). Does tourism cause growth? Evidence from Turkey. Current Issues in Tourism, 19(12), 1176-1184.

Balaguer, J. And Cantavella-Jorda, M. (2002). Tourism as a long-run economic growth factor: the Spanish case. Applied economics, 34(7), 877-884.

Belloumi, M. (2010). The relationship between tourism receipts, real effective exchange rate and economic growth in Tunisia. International Journal of Tourism Research, 12(5), 550-560.

Breitung, J. and B. Candelon (2006), Testing for short- and long-run causality: A frequency domain approach, Journal of Econometrics 132, 363-379.
Brida, J. G., Pereyra, J. S., \& Devesa, M. J. S. (2008). Evaluating the contribution of tourism to economic growth. Anatolia, 19(2), 351-357.

Brida, J. G., Sanchez Carrera, E.J. and Risso, W.A. (2008). Tourism's Impact on LongRun Mexican Economic Growth. Economics Bulletin, 3(21), 1-8

Clive W.J., \& Lin, J. L. (1995). Causality in the long run. Econometric Theory, 11(3), 530536.

Cortes-Jimenez, I., \& Pulina, M. (2010). Inbound tourism and long-run economic growth. Current Issues in Tourism, 13(1), 61-74.

Demiroz, D. M., \& Ongan, S. (2005). The contribution of tourism to the long-run Turkish economic growth. Ekonomický časopis, 9, 880-894.

Ding, M., Y. Chen and S.L. Bessler (2006), Granger Causality: basic Theory and Application to Neuroscience, B. Schelter, M. Winterhalder and J. Timmer (eds.) Handbook of Time Series Analysis. Wiley: 437-460.

Dritsakis, N. (2004). Tourism as a long-run economic growth factor: an empirical investigation for Greece using causality analysis. Tourism Economics, 10(3): 305316.

Durbarry, R. (2004). Tourism and economic growth: the case of Mauritius. Tourism Economics, 10(4), 389-401.

Ertugrul, H. M., \& Mangir, F. (2015). The tourism-led growth hypothesis: empirical evidence from Turkey. Current Issues in Tourism, 18(7), 633-646.

Geweke, J. (1982). Inference and causality in economic time series models. University of Wisconsin Social Systems Research Institute.

Ghosh, S. (2011). Examining tourism-led growth hypothesis for India. International Journal of Indian Culture and Business Management, 4(3), 347-355.

Gokovali, U. (2010). Contribution of tourism to economic growth in Turkey. Anatolia, 21(1), 139-153.

Granger, C. W. (1969). Investigating causal relations by econometric models and cross-spectral methods. Econometrica: Journal of the Econometric Society, 424438. 
Frequency domain causality analysis of tourism and economic activity in Turkey.

Gunduz, L., \& Hatemi-J, A. (2005). Is the tourism-led growth hypothesis valid for Turkey? Applied Economics Letters, 12(8), 499-504.

Hosoya, Y. (1991). The decomposition and measurement of the interdependency between second-order stationary processes. Probability theory and related fields, 88(4), 429-444.

Jackman, M., \& Lorde, T. (2010). On the relationship between tourist flows and household expenditure in Barbados: A dynamic OLS approach. Economics Bulletin, 30(1), 472-481.

Kasimati, E. (2011). Economic impact of tourism on Greece's economy: Cointegration and causality analysis. International research journal of Finance and Economics, 79(5), 79-85.

Katircioglu, S. T. (2009). Revisiting the tourismled-growth hypothesis for Turkey using the bounds test and Johansen approach for cointegration. Tourism Management, 30(1), 17-20.

Katircioglu, S. T. (2010). International tourism, higher education and economic growth: The case of North Cyprus. The World Economy, 33(12), 1955-1972.

Krätschell, K., \& Schmidt, T. (2012). Long-run Trends or Short-run Fluctuations-What Establishes the Correlation between Oil and Food Prices? The Interplay of Standardized Tests and Incentives - An Econometric Analysis with Data from PISA 2000 and PISA 2009, Ruhr Economic Papers, No. 357, ISBN 978-3-86788-4112, RWI, Essen

Kumar, R. R. (2014). Exploring the nexus between tourism, remittances and growth in Kenya. Quality \& Quantity, 48(3), 15731588.

Kumar, R. R., \& Kumar, R. (2012). Exploring the nexus between information and communications technology, tourism and growth in Fiji. Tourism Economics, 18(2), 359-371.

Kumar, R. R., \& Stauvermann, P. J. (2016). The linear and non-linear relationship between of tourism demand and output per worker: A study of Sri Lanka. Tourism Management Perspectives, 19, 109-120.

Li, C. C., Mahmood, R., Abdullah, H., \& Chuan, O. S. (2013). Economic growth, tourism and selected macroeconomic variables: A triangular causal relationship in Malaysia. Margin: The Journal of Applied Economic Research, 7(2), 185-206.

Liu, S., \& Molenaar, P. (2016). Testing for Granger causality in the frequency domain: A phase resampling method. Multivariate behavioral research, 51(1), 53-66.

Nuryanti, W. (1998). Tourism and regional imbalances: The case of Java. Indonesia and the Malay World, 26(75), 136-144.

Oh, C. O. (2005). The contribution of tourism development to economic growth in the Korean economy. Tourism management, 26(1), 39-44.

Ohlan, R. (2017). The relationship between tourism, financial development and economic growth in India. Future Business Journal, 3(1), 9-22.

Ozer, M., \& Kamisli, M. (2015). Frequency domain causality analysis of interactions between financial markets of Turkey. International Business Research, 9(1), 176-186.

Pavlic, I., Svilokos, T., \& Tolic, M. S. (2015). Tourism, real effective exchange rate and economic growth: Empirical evidence for Croatia. International Journal of Tourism Research, 17(3), 282-291.

Phiri, A. (2016). Tourism and economic growth in South Africa: Evidence from linear and nonlinear cointegration frameworks. Managing Global Transitions, 14(1), 31-53.

Ridderstaat, J., Croes, R., \& Nijkamp, P. (2014). Tourism and Long-run Economic Growth in Aruba. International Journal of Tourism Research, 16(5), 472-487.

Schubert, S. F., Brida, J. G., \& Risso, W. A. (2011). The impacts of international tourism demand on economic growth of small economies dependent on tourism. Tourism Management, 32(2), 377-385.

Shahzad, S. J. H., Shahbaz, M., Ferrer, R., \& Kumar, R. R. (2017). Tourism-led growth hypothesis in the top ten tourist destinations: New evidence using the quantile-on-quantile approach. Tourism Management, 60, 223-232.

Tang, C. F., \& Abosedra, S. (2016). Tourism and growth in Lebanon: New evidence from bootstrap simulation and rolling causality approaches. Empirical Economics, 50, 679-696. 
Tang, C. F., \& Ozturk, I. (2017). Is tourism a catalyst of growth in Egypt? Evidence from Granger non-causality and the generalised variance decomposition analysis. Anatolia, 28(2), 173-181.

Tang, C. F., \& Tan, E. C. (2015). Tourism-led growth hypothesis in Malaysia: Evidence based upon regime shift cointegration and time-varying Granger causality techniques. Asia Pacific Journal of Tourism Research, 20(1), 1430-1450.
Tiwari, A.K., Mutascu,M.I., Albulescu, C.T.,\& Kyophilavong, P. (2015). Frequency domain causality analysis of stock market and economic activity in India. International Review of Economics and Finance, 39, 224-238.

Yıldırım, J., \& Öcal, N. (2004). Tourism and economic growth in Turkey. Ekonomik Yaklaşım, 15(52-53), 131-141. 